Rev. Adm. Saúde Vol. 17, № 69, Out. - Dez. 2017

http://dx.doi.org/10.23973/ras.69.60

EDITORIAL

\title{
Gestão de pessoas na saúde
}

\author{
Haino Burmester ${ }^{1}$ \\ 1. Médico, administrador hospitalar e de sistemas de saúde. Coordenador do Programa CQH
}

Qualquer ação eficaz, mesmo nas grandes empresas, ocorre num nível pessoal. À medida que se caminha para um mundo de equipes de trabalho autogeridas com menos comando e menos controle da gerência, a maneira como se lida com as pessoas é fundamental. Numa organização comprometida com a tarefa de melhorar constantemente seu desempenho, as equipes representam instrumento fundamental para a excelência gerencial. No caso de organizações de saúde, onde o serviço é prestado sobre pessoas fragilizadas pela doença e vulneráveis em sua sensibilidade, mais do que em qualquer outra empresa, o fator humano é fundamental. A humanização no atendimento não pode ser considerada como um fim em si mesmo, mas consequência de uma ação integrada que leve à excelência gerencial e como consequência, à assistência humanizada. Esforços para humanizar organizações de saúde, fora de um contexto gerencial que crie condições para isso, são pouco eficazes; melhor seria concentrar esforços em desenvolver um modelo de gestão sistêmico, integrado e que crie condições para que o atendimento humanizado aconteça naturalmente e não artificialmente.

É muito comum falar sobre a valorização das pessoas sem que esta intenção venha acompanhada de ações concretas. O discurso da valorização das pessoas é o politicamente correto e ninguém ousa contradizê-lo, porem atuar de acordo com ele nem sempre é o que se vê na prática. Quase todos se vangloriam, em público, de que "as pessoas são o maior capital que tem a empresa", mas as ações praticadas nem sempre se coadunam com esta afirmação. É preciso deixar a hipocrisia de lado quando se trata de fazer boa gestão de pessoas porque ninguém engana ninguém.

Os produtos e serviços das organizações de saúde em geral e dos hospitais em particular, tornam-se cada vez mais complexos exigindo uma cultura de excelência gerencial humanizada, para compensar pela avassaladora presença da tecnologia intermediando os contatos humanos. É preciso sempre relembrar que serviços médico-hospitalares são prestados por pessoas para pessoas. $O$ sucesso de uma organização depende cada vez mais do conhecimento, habilidades, criatividade e motivação das pessoas que nela trabalham. $O$ 
sucesso das pessoas por sua vez, depende cada vez mais de oportunidades para aprender e de um ambiente favorável ao pleno desenvolvimento de suas potencialidades.

Neste contexto, a promoção da participação das pessoas em todos os aspectos do trabalho destaca-se como um elemento fundamental para obtenção da sinergia dentro das equipes. Pessoas com habilidades e competências distintas formam equipes de alto desempenho quando lhes é dada autonomia para alcançar metas bem definidas. A valorização das pessoas leva em consideração a diversidade de anseios e necessidades que, uma vez identificados e utilizados na definição das estratégias, dos planos e das práticas de gestão, promovem o desenvolvimento, o bem-estar e a satisfação delas. As organizações e os hospitais mais do que quaisquer outras empresas são feitas de pessoas. São as pessoas que trabalham num e noutro hospital, que os diferenciam entre si. Num mundo competitivo em que tecnologias estão ao alcance de quem tenha dinheiro para comprá-las (e se não tem dinheiro, pode financiá-las), assim como a construção de instalações físicas também está ao alcance de todos, o fator diferencial entre empresas é o potencial humano de que ela dispõe. São as pessoas que podem criar novas condições para a empresa, adaptando-a e flexibilizando-a conforme as necessidades do meio ambiente. Portanto, valorizar as pessoas deve ser mais do que uma figura retórica de efeito demagógico. É preciso que seja entendido que a empresa depende de pessoas para formar a sua força de trabalho, sem a qual ela nada produzirá. Sem falar nas pessoas que constituem o mercado comprador. Valorizar as pessoas significa permitir que elas desenvolvam todo seu potencial humano e profissional dentro da empresa, a fim de que elas possam se realizar integralmente. O sucesso de uma organização depende cada vez mais do conhecimento, das habilidades, da motivação e da criatividade de sua força de trabalho. Por sua vez, o sucesso das pessoas depende cada vez mais das oportunidades para aprender, experimentar novas habilidades e utilizar a criatividade. As organizações necessitam investir continuamente no desenvolvimento das pessoas por meio de educação, de treinamento e de novas oportunidades de crescimento profissional. Essas oportunidades podem incluir:

- Treinamento em sala de aula e na execução da atividade;

- Rodízio de funções; ou

- Remuneração baseada no conhecimento na habilidade e na criatividade.

O treinamento na execução da atividade oferece uma forma eficaz de reduzir o custo de treinamento e de melhorar sua integração com os processos de trabalho. Os programas de educação e treinamento podem requerer a utilização de tecnologias avançadas como sistemas eletrônicos de apoio, aprendizado informatizado ou telecursos. O treinamento, o desenvolvimento e a organização do trabalho precisam, cada vez mais, ser ajustados à diversidade de pessoas e às práticas de trabalho mais flexíveis e de alto desempenho. Além disso, os aspectos de remuneração baseada em resultados, de "empregabilidade", de saúde e segurança no trabalho e de 
envolvimento nos processos de planejamento estratégico, decisório, padronização de rotinas, definição de necessidades de treinamento e melhoria contínua, dentre outros, devem ser enfatizados. Os maiores desafios, no que se refere ao desenvolvimento de pessoas são:

- A integração das práticas de recrutamento, seleção, desempenho, reconhecimento, treinamento, progresso profissional, substituição e afastamento;

- A gestão da mudança, ou seja, o alinhamento da gestão de pessoas com os processos de mudança estratégica.

A abordagem desses desafios requer a utilização de informações relativas ao conhecimento, habilidades, criatividade, satisfação, motivação, prevenção de acidentes de trabalho e bem-estar das pessoas. Essas informações devem estar vinculadas a indicadores que reflitam a satisfação de clientes e a produtividade da força de trabalho. Por meio desse enfoque, a gestão de pessoas pode ser mais bem integrada e alinhada às estratégias da organização. Qualquer que seja o modelo de gestão praticado pelo hospital, ele deverá englobar três itens: os sistemas de trabalho; a educação, treinamento e desenvolvimento; e o bem-estar e a satisfação das pessoas.

Recebido em: 11 outubro 2017. Publicado em: 16 outubro 2017

Endereço para correspondência: Haino Burmester. Avenida Brigadeiro Luís Antônio, 278 - 7ํandar. CEP 01318-901. São Paulo - SP. E-mail: cqh@apm.org.br 